\title{
An Outlook on the Research Trends of the Stability of Industrial Technology Innovation Strategic Alliance
}

\author{
Lixian Guo \\ Panyapiwat Institute of Management \\ Bangkok, Thailand \\ 279350605@qq.com
}

\author{
Lisheng Yang* \\ Yunnan Nationalities University \\ Kunming, China \\ 279350605@qq.com
}

\begin{abstract}
Industrial Technology Innovation Strategic Alliance, as a new mode combining production, education and research, has attracted more and more attention. However, as the operating efficiency of the Alliance is not satisfied, the stability of the Alliance becomes the research focus. This paper, on the basis of literal review, points out the deficiency of current research and takes a look on the future research trends, which will lay a solid foundation on its theoretical and empirical study. Furthermore, it provides a reference for the steady operation and consistent development of Industrial Technology Innovation Strategic Alliance under the background of promoting China's "Belt and Road Initiative".
\end{abstract}

Keywords—technology innovation; strategic alliance; stability; trends; outlook

\section{INTRODUCTION}

Since the establishment of China's first batch of Industrial Technology Innovation Strategic Alliance in 2007, it has been blooming everywhere. As an innovative mode of deepening cooperation among production, education and research, it has become an important magic weapon for enterprises to overcome technical difficulties, cultivate independent innovation capability, and access to competitive advantage so as to boost the building of an innovative country. However, what confuses many enterprises and scholars is that the failure rate of the Alliance has always been high. Therefore, scholars began to explore ways to reduce the failure rate of the Alliance, and ultimately put their standing point on the stability of the Alliance. With the implementation of China's "Belt and Road Initiative", Yunnan and its neighboring South Asia, Southeast Asian countries and research institutions will seek a higher-level cooperation and exchange in a larger range and at a higher level. This paper summarizes current research trends on the stability of industrial technology innovation strategic alliance, pointing out its deficiency, and taking a look on the future research trend. It is conducive to the theoretical research under the background of China's "Belt and Road Initiative" and thus provides guidance for the stable operation and sustainable development of Industrial Technology Innovation Strategic Alliance.

\section{LITERATURE REVIEW}

\section{A. About Researches on the Stability of Industrial} Technology Innovation Strategic Alliance

The definition of Industrial Technology Innovation Strategic Alliance in China comes from the "Guidance on Promoting the Building of Industrial Technology Innovation Strategic Alliance" (hereafter referred to as the guidance), which was jointly issued by the Ministry of Science and Technology and other six departments in December, 2008. The guidance pointed out that industrial technology innovation strategic alliance includes enterprises, universities, and scientific research institutions or other organizations. On the basis of the development needs of enterprises and common interests of all parties, it aims at enhancing the technological innovation capability. It is a technological innovation cooperation organization featured with joint development, complementary advantages, shared benefits and risks under the protection of a legally binding Contract. Research on the stability of industrial technology innovation strategic alliance begins from the stability study of the Alliance. To sum up, it mainly focuses on the following aspects:

1) About Researches on the Choose of Alliance Partner, Resource Input and Stability

About researches on the influence of choosing Alliance partner on its stability, Candace (2009) [1] who conducted an empirical study on enterprises involved in the technology alliance between 1996 and 1999, found that direct competition was more risky than the opportunism of selecting alliances. So technology alliance is preferred by a large number of enterprises. Das and Teng (2003) [2] analyzed risks in the Alliance and found that in terms of interest sharing, enterprises incline to pursue the maximization of their own interests, and at the same time prevent others from overpursuing interests. This makes a higher risk in an alliance than that in an independent company. Yang Guang (2009[3] adopted the theory of social capital investment to study the stability of alliance, while Xing Lebin (2010) [4]constructed a growth model of total resources of the members in the Alliance. Xing points out that the stability of the Alliance depends on any member of the alliance, because of the

*Corresponding author 
negative impact of resource input on the alliance and relative resources when absorbing resource.

\section{2) About Researches on Factors that Influence the} Stability of Alliance

Researches on factors that influence the stability of alliance are mainly based on the basic theory of resources and the theory of transaction cost with few empirical research. Yan \& Zeng (1999) [5], on the basis of alliance performance, suggested that after an restructuring in terms of strategic direction, alliance agreement or organizational structure, the parent subsidiary company relationship begins to change and thus affects the performance of the Alliance, which causes the instability in Alliance. David (2003) [6] pointed out that improving the competencies of members of the Alliance, such as communication skills and behavioral coherence, is an effective measure to ease Alliance conflicts and eliminate destabilizing factors. Gill (2003) [7] argued that key factor in the stability of the Alliance is the degree of trust, conflict and dependence. The stability of resource allocation is an important indicator of the stability of the technological innovation alliance. Aharoni (2010) [8] and others analyzed the influence of cultural differences on the stability of the Alliance.

Many domestic scholars have classified and divided factors that influence the stability of the Alliance, such as endogenous factors and exogenous factors (Liu Yun 、 Liang Dongguo, 2007) [9]; flexible factors and rigid factors (Chen Feiqiong, Wen Lili, 2008) [10]; congenital factors and acquired factors (Ma Bin, Zhang Guoyan, 2011) [11] and so on. Zeng Xiaozhou (2008) [12] and others, on the basis of integrity, analyzed the main factors influencing the stability of strategic alliance, and then built an evaluation index system for the stability of strategic alliance. Jiang Zhangsheng (2009)[13] from the perspective of knowledge transfer, explored the stability of technological innovation alliance. Cai Jirong (2012)[14], from the perspective of resource theory, transaction cost theory and game theory, combed the evolution of strategic alliance stability and analyzed factors influencing the stability of the Alliance. Chen Jia (2012)[15],argued that factors affecting the stability of the Alliance are organizational capacity, organizational trust, relationship type, sharing mechanism, benefit distribution mechanism and communication and coordination mechanism. Yuan Yijun (2013)[16], from the perspective of system dynamics, established a system flow diagram and a dynamic model of the stability of the Alliance. His research shows that external variables such as reputation, cooperation experience, resources and scale endowments and other factors have a weak influence on the stability of the Alliance, while internal variables such as trust, speculation, and profit distribution have a greater impact on the stability of the Alliance.

3 ) About Researches on System Structure, Trust Relationship and the Stability of Alliance

About researches on system structure and alliance stability, Bruhn (1995)[17],found that the instability of industrial technology strategic alliance mainly came from internal conflicts and incoordination. Nader (2005)[18], argued that under emerging organizations, enterprises can benefit from direct alliance, and indirect alliance is also beneficial to the business. Kim (2008) [19],found that factors like alliance management structure, behavior control, output control and social control are key factors to enhancing alliance trust and mitigate risks.

About researches on trust relations and the stability of the Alliance, Ybarra (2009) [20],found that higher instability and dependency make the trust between members a key factor in the success of the Alliance. Cai Jirong (2006)[21],took the competitive alliance of China's automobile industry as an empirical object, and analyzed and validated the effect of alliance partners' characteristics and mechanism like credible commitment on the stability of the alliance. Zhang Ming and Jiang $\mathrm{Xu}$ (2008)[22],studied the stability of the alliance from the perspective of alliance trust mechanism, and proposed that trust and control are two ways to reduce the risk of alliance. Jiang Xu and Gao Shanxing (2009)[23],further improved the definition of the stability of the alliance, pointing out that stability includes features like dynamic, process-based and multidimensional structure and the overall stability of the alliance is determined by the stability of the alliance partnership mechanism. They finally put forward using second - order factor analysis structure to measure the stability of the Alliance.

4) Studies on the Quantitative Analysis of the Stability of the Alliance

About the role of game theory in the stability of the Alliance, Parkhe(1993)[24],holds the cooperation among the members of the Alliance as a game playing of payoff function that is similar to prisoner's dilemma. Kale [25], believes that there are risks and threats including responsibility shifting, cheat and distortion in the partnerships and puts forward corresponding measures. Zhao [26] makes a research on the stability of the Alliance with game theory and conducts empirical analysis. Jiang Zhangsheng [27], on the basis of Bayesian Game Model, establishes a decision equation on the ground of prediction of investment income and points out that the more members the Alliance takes in, the more stably it operates. However, return expectations of the members, indeterminacy of the external environment and negative externality exert unfavorable effects on the stability of the Alliance. Jiang \& Hao [28] analyzes the cooperation and stability of the Alliance by employing game theory. Song \& Huang [29] have analyses on the stability of strategic alliance by applying hawk-dove game model in the perspective of asymmetric cooperation.

About the role of symbiosis model in the stability of the Alliance, Chen \& Fan [30] in the light of Das \& Teng's inherent tension frame and with the guidance of Symbiosis Theory, argue that the instability of the Alliance grows with the gap formed between cooperation and competition in the Alliance. Feng Lumin [31] instructed by Logistic Model, analyzes the stability of the Alliance in Parasitic Model, Commensalism Model and asymmetric mutualism. Liu Linzhou [32] regards the Alliance as a symbiotic ecosystem. Based on the analyses of the stability of the Alliance, he builds Lorka-Volterra Equation, which studies the stability of the Alliance through analyzing curve trends. He concludes 
that the Alliance will operate stably when its members are in mutualistic symbiosis.

\section{5) Studies on the Enhancement of the Tactics for the} Stability of the Alliance

Nakamura [33] proposes that the stability of the Alliance will be improved by growing the abilities of bargain and learning from the membership. Ernst [34] deems that a stable alliance is apt to adjust itself to the changes of the membership in a timely and persistent manner, and is adaptable to reallocation of resources and structure engineering. Birnbirg [35] conducts researches on tactics conducive to stable operation in five aspects, which are, level of absolute and relative input, symmetry of returns, degree of trust, extent of indeterminacy and age of the Alliance. $\mathrm{Xu}$ Libo [36] on the foundation of interdependent balance theory, analyzes the role of value creation in stable operation of the Alliance and concludes that social capital stays in stability by facilitating interdependence and the balance of membership. $\mathrm{Xu}$ Han [37] raises incentives to promote the stability of strategic alliance of industrial technology innovation under the system of E-HR.

\section{ANALYSIS AND DISCUSSION}

\section{A. Limits in Current Researches}

In general, based on different theoretical views, scholars discussed the stability of the strategic alliance of industrial technology innovation and achieved some results. However, the stability of the Alliance is a complex system, and there are some limits in current researches from both theories and practices, which are:

First, there has been a long discussion about the stability of the Alliance, but in China, based on the strategy of innovation-driven development, especially the background of the "Belt and Road Initiative", this study is still in its primary stage, which embodied in a lack of systematicness and comprehensiveness. Theoretical framework needs a further enrichment and perfection.

Second, many studies at present focus on macroscopic policies, and so the model application and data empirical research are insufficient, which result in a lack of interpretation of dynamic stability rules of the Alliance. The quantitative and empirical tests also need to be further enriched and perfected.

\section{B. Research Trends}

With the acceleration of the global integration process and the implementation of China's "Belt and Road Initiative", the combination of Alliances from all over the world will bring us new opportunities for development. Our future research should improve the interaction between theory and practice to strengthen the guidance and practicability of theoretical research. For example, we can study strategic alliance from the perspective of new economic sociology because it introduces the concept of social capital. Based on it, more indepth researches can be done from the aspects such as trust, network embedded types, and more effective operating mechanism can be studied from the aspects of social network so as to enlighten new research ideas. In addition, because the Alliance aims at solving the problem of generic technology, In order to better promote the construction of stability of industrial technology innovation strategic alliance, combined with the problems existing in the current study, the research should be vigorously strengthen its breadth and depth, through the questionnaire, interview and discussion, field survey and other research methods which can collect the related raw materials and construct related coordinated management theory system of the Alliance. At the same time, by using the structural equation model, the system dynamics model, econometric model and related research methods, the field of research will be wider from different perspectives. so more attention should be given to technology coordinated management in each alliance through quantitative analysis and empirical studies in order to preferably promote the construction of alliance stability and improve competitiveness.

\section{CONCLUSIONS}

Strategic alliance of industrial technology innovation is just one form of strategic alliance in China, so its stability is directly related to the Alliance's healthy operation and sustainable development. Based on the background of the "Belt and Road Initiative" and innovation-driven development strategy which Chinese government strongly advocated, this paper deals with the literature research achievements, discusses its limits and research trends in the future, which will be of great importance in conducting further theoretical research and in guiding and promoting the interaction and collaboration of the international Alliance.

\section{ACKNOWLEDGEMENT}

My deepest gratitude goes first and foremost to professor Duan Yunlong, my supervisor, for his constant encouragement and guidance. I am also greatly indebted to professor Liu Er'si, professor Zhou Wei, associate professor Wang Fan, associate professor Gan Jiawu, who have instructed and helped me work out my problems during the difficult course of the thesis. The paper was supported by National Natural Science Foundation of China(71663058), (71663062), (71262016)

\section{REFERENCES}

[1] E. Candace, and A.T. Thomas, "The evolution of trust in information technology alliances," Journal of High Technology Management Research,2009, pp. 62-74.

[2] T.K. Das, and B. Teng, "Partner analysis and alliance performance," Scandinavian journal of management, vol. 19, 2003, pp. 279-308.

[3] G. Yang "Business Friendships among Senior managers and Research on the Stability of Technology Innovation Strategy Alliance," Science of Science and Management of S.\& T, vol. 30, 2009, pp. 197-199.

[4] L.B. Xing, X. Wang, and Y. Dai, " A Study on the Stability of Technology Innovation Strategy Alliance Based on Resources Input," Science \& Technology Progress and Policy, vol. 27, 2010, pp. 1-4.

[5] A. Yan, and M. Zeng, "International joint venture instability: a critique of previous research, a reconceptualization, and directions for future research," Journal of International Business Studies, vol. 30, 1999, pp. 397-414. 
[6] F. David, L. Disne, and V. John, "A real options approach to valuing strategic edibility In uncertain construction projects," Construction Management and Economics, vol. 20, 2003, pp. 343-351.

[7] J. Gill, and R.J. Butler, "Managing instability in cross-cultural alliances," Lon Range Planning, vol. 36, 2003, pp. 543-563.

[8] Y. Aharoni, and D.M. Brock, "International business research: looking back and looking forward," Journal of International Management, 2010, pp. 5-15.

[9] Y. Liu, and D.G. Liang, "Analysis and Evaluation of Factors Influencing the Stability of MNC Technology Alliances," Science of Science and Management of S.\& T, 2007, pp. 5-8.

[10] F.Q. Chen, and L.L. Wen, "Stabilities of Alliances: The Tension of Flexibility and Rigidity Perspective," Journal of Zhejiang University (Humanities and Social Sciences), vol. 11, 2008, pp. 166-171.

[11] B. Ma, and G.Y. Zhang, "A Research about the Impact Factors in the Stability of Strategic Alliances Among Enterprises," Social Sciences Journal of Universities in Shanxi, vol. 1, 2011, pp. 40-43.

[12] X.Z. Zeng, and K.S. Jiang, "A Research about the Impact Factors in the Stability of Strategic Alliances under the perspective of Honesty," Prices Monthly, vol. 2, 2008, pp. 78-79.

[13] Z.S. Jiang, and L.Y. Hu, "Effects of Knowledge Acquisition Ability on the Stability of Technology Innovation Alliance under Uncertainty," Journal of Industrial Engineering and Engineering Management, vol. 4, 2010, pp. 41-46.

[14] J.R. Cai, "Partner Characteristics, Credible Commitment and the Stability of Strategic Alliances," Science of Science and Management of S.\& T, vol. 33, 2012, pp. 133-142.

[15] J. Chen, "An Analysis on the Governance Mode of Strategic Alliances for Industrial Technology Innovation," Science and Technology Management Research, 2011, pp. 2-3.

[16] Y.J. Yuan, Y. Tian, and J. Sun, "Modeling and Simulation of IndustryUniversity-Research Technical Alliance Stability Using System Dynamics," Science of Science and Management of S.\& T, vol. 4, 2013, pp. 4-8.

[17] Bruhn, "Strategic alliance attracting: A game theory and transaction cease examination of interterm cooperation," Academy of Management Journal,1995, pp. 794-829.

[18] Nader, "The institutional arrangements of innovation: antecedents and performance effects of trust in high-tech alliances," Industry\& Innovation, vol. 15, 2005, pp. 45-67.

[19] L.S. Kim, "The relations between transaction characteristic, trust and risk in the Start-up phase of a collaborative alliance," Management Accounting Research, vol. 19, 2008, pp. 344-364.

[20] H. Yasuda, "Formation of strategic alliances in high-technology industries:comparative study of the resource-based theory and the transaction-cost theory," Technovation, vol. 25, 2009, pp. 763-770.

[21] J.R. Cai, and P. Hu, "Analysis on the Stability of Strategic Alliance Abroad," Foreign Economics \& Management, vol. 28, 2006, pp. 34-41.
[22] M. Zhang, and X. Jiang, "An empirical investigation of organizational learning, knowledge creation and innovative performance in strategic alliances," Studies in Science of Science, vol. 26, 2008, pp. 868-873.

[23] X. Jiang, and S.X. Gao, "The Scope, Governance and Stability of Strategic Alliances Evidence from German Firms," Journal of Industrial Engineering and Engineering Management, 2009, pp. 1-6.

[24] A. Parkhe, "Strategic alliance structuring: a game theory and transaction cost examination of inter-firm cooperation," Academy of Management Journal,1993, pp. 794-829.

[25] P. Kale, and H. Singh, "The stability of strategic alliance: Characteristics, factors and stages," Journal of International Management, 2008, pp. 173-189.

[26] M.G. Zhao, "Analysis of the granularity of task decomposition in enterprise alliance based on system dynamics", Machinery Design \& Manufacture, 2010, pp. 314-316.

[27] Z.S. Jiang, "Analysis on the Stability of Strategic Alliance based on Investment Income Prediction under Incomplete Information," Statistics and Decision-making, 2012, pp. 41-45.

[28] Z.S. Jiang, and Y.H. Hao, "Game analysis of technology innovation alliance stability based on knowledge transfer," Computational \& Mathematical Organization Theory, vol. 19, 2013, pp. 403-421.

[29] B. Song, and J. Huang, "Analysis on the Stability of Strategic Alliance from Asymmetric Cooperation Perspective," Soft Science, vol. 27, 2013 , pp.28-31.

[30] F.Q. Chen, and L.C. Fan, "Research on Stability of Industrial Technology Innovation Alliance based on Cooperation and Competition," Management World, 2007, pp. 102-110.

[31] L.M. Feng, "Research on Stability of Industrial Technology Innovation Alliance based on Symbiotic Theory," Nanjing University of Posts and telecommunications, 2012, pp. 7-15

[32] L.Z. Liu, B. Wu, and W.X. Sun, "Research on Development Model of Stability of Industrial Technology Innovation Alliance," Science \& Technology Progress and Policy, vol. 29, 2012, pp. 62-64.

[33] M. Nakamura, "Joint venture instability, learning and the relative bargaining power of the parent firms," International Business Review, vol. 14, 2005, pp. 465- 493.

[34] D. Ernst, and J. Bamford, "Your alliances are too stable," Harvard Business Review, vol. 83, 2005, pp. 133-141.

[35] J.G. Birnbirg, "Using strategic alliances to make decisions about investing in technological innovations," International Journal of Management, vol. 23, 2006, pp. 195-197.

[36] L.B. Xu, and J.J. Shi, "Dynamic Stability for Alliance: Theory Based on Interdependence Balance," China Industrial Economics, 2010, pp. 97 106.

[37] H. Xu, and J. Ge, "Research on Human Resource Integration Ways in Stability of Industrial Technology Innovation Alliance under the System of E-HR," China Economic \& Trade Herald, pp. 50-51. 